\title{
Structural basis of human $\beta$-cell killing by CD8+ T cells in Type 1 diabetes
}

\author{
Anna M. Bulek $1,{ }^{*}$, David K. Cole ${ }^{1,{ }^{*}}$, Ania Skowera $2,3,{ }^{*}$, Garry Dolton ${ }^{1}$, Stephanie Gras ${ }^{4}$, \\ Florian Madura ${ }^{1}$, Anna Fuller ${ }^{1}$, John J. Miles ${ }^{1}$, Emma Gostick ${ }^{1}$, David A. Price ${ }^{1}$, Jan W. \\ Drijfhout $^{6}$, Robin R. Knight ${ }^{2}$, Guo C. Huang ${ }^{7}$, Nikolai Lissin ${ }^{5}$, Peter E. Molloy ${ }^{5}$, Linda \\ Wooldridge $^{1}$, Bent K. Jakobsen ${ }^{5}$, Jamie Rossjohnn ${ }^{1,4}$, Mark Peakman ${ }^{2,3},{ }^{*}$, Pierre J. \\ Rizkallah $^{1, *}$, and Andrew K. Sewell ${ }^{1,{ }^{*}}$
}

${ }^{1}$ Cardiff University School of Medicine, Heath Park, Cardiff, CF14 4XN, UK ${ }^{2}$ Department of Immunobiology, King's College London, London, UK ${ }^{3}$ NIHR Biomedical Research Centre at Guy's \& St Thomas' NHS Foundation Trust and King's College London, London, UK ${ }^{4}$ The Protein Crystallography Unit, Department of Biochemistry and Molecular Biology, School of Biomedical Sciences, Monash University, Clayton, Victoria 3800, Australia 5 Immunocore Ltd., 57c Milton Park, Abingdon, UK ${ }^{6}$ Department of Immunohematology and Blood Transfusion, Leiden University Medical Centre, Leiden, Netherlands. ${ }^{7}$ Diabetes and Nutritional Science King's College London, London, UK

\section{Abstract}

The structural characteristics of autoreactive-T cell receptor (TCR) engagement of major histocompatability (MHC) class II-restricted self-antigens is established, but how autoimmuneTCRs interact with self-MHC class I has been unclear. We examined how $\mathrm{CD} 8^{+} \mathrm{T}$ cells kill human islet $\beta$-cells, in Type-1 diabetes, via autoreactive-TCR (1E6) recognition of an HLAA*0201-restricted glucose-sensitive preproinsulin peptide. Rigid 'lock-and-key' binding underpinned the 1E6-HLA-A*0201-peptide interaction, whereby 1E6 docked similarly to most MHCI-restricted TCRs. However, this interaction was extraordinarily weak, due to limited contacts with MHCI. TCR binding was highly peptide-centric, dominated by two CDR3-loopencoded residues, acting as an 'aromatic-cap', over the peptide MHCI (pMHCI). Thus, highly focused peptide-centric interactions associated with suboptimal TCR-pMHCI binding affinities might lead to thymic escape and potential $\mathrm{CD} 8^{+} \mathrm{T}$ cell-mediated autoreactivity.

\footnotetext{
* These authors contributed equally to this study AUTHOR CONTRIBUTIONS D.K.C., P.J.R., M.P. and A.K.S led the investigation and conceived the project. D.K.C. and A.M.B. performed crystallization and surface plasmon resonance studies. D.K.C., A.M.B., F.M., J.J.M., P.J.R. and A.F. collected data and harvested crystals. D.K.C., S.G. and P.J.R. performed crystallographic analysis. A.S., J.W.D. and R.R.K. performed the cellular experiments. G.C.H. prepared the human islets. G.D. cultured T cells. E.G., N.K., P.E.M. cloned the 1E6 TCR. D.K.C., A.K.S., M.P., P.J.R., J.J.M. J.R., S.G. wrote the manuscript. L.W., B.K.J. intellectual input. A.K.S., M.P., D.A.P., J.R. funded the study.

METHODS Methods and any associated references are available in the online version of the paper at http://www.nature.com/ natureimmunology/.

Accession codes: Protein data bank: 1E6-A2-ALW complex (P1 space group), 3UTS; 1E6-A2-ALW complex (P21 space group), 3UTT; 1E6 TCR, 3UTP; A2-ALW, 3UTQ.
}

Note: Supplementary information is available on the Nature Immunology website.

COMPETING FINANCIAL INTERESTS The authors declare no competing financial interests. 


\section{Keywords}

$\beta$-cell; crystal structure; peptide-major histocompatibility complex (pMHC); preproinsulin; surface plasmon resonance (SPR); T cell; T cell receptor (TCR); type 1 diabetes (T1D); vaccine

The major histocompatibility complex (MHC) on human chromosome 6 is the most important genetic locus for human autoimmune diseases, indicating that $\mathrm{T}$ cell recognition of self antigens initiates and drives pathology ${ }^{1,2}$. Most, but evidently not all, self-reactive $\mathrm{T}$ cells are eliminated in the thymus by negative selection ${ }^{3}$. Hence, there is a pressing need to better understand the molecular interactions through which disease-relevant $\mathrm{T}$ cell receptors (TCRs) bind to self-derived peptide-MHC (pMHC) ligands and escape thymic negative selection to populate the periphery. Structural studies of numerous non-autoimmune TCRpMHC complexes have demonstrated that this can be a variable and versatile interaction ${ }^{4-14}$ in which a prototypic diagonal TCR-pMHC docking mode is utilized with the variable (V)a and V $\beta$ domains of the TCR positioned over the a2- and a 1-helices of the MHC molecule, respectively ${ }^{4,15}$. In contrast, the current structural database for human autoantigen-reactive TCRs in complex with their self-ligands is highly limited. Three complexes exhibit atypical binding properties when compared to pathogen-specific TCR-pMHC complexes ${ }^{13}, 16,17$, such as a predominant focus on the $\mathrm{N}$-terminal region of the peptide or excessive tilting ${ }^{13}$, 16 , leading to the notion that autoreactive TCRs have an abnormal docking mode. However, only four structures in total have been described to date and all are MHCIIrestricted and specific for myelin basic protein $(\mathrm{MBP})^{13,14,16,17}$, an autoantigen targeted in multiple sclerosis. At present, no structural or molecular data exist for other human autoimmune diseases. More importantly, there has been no exploration of the molecular interaction between an autoreactive TCR and pMHCI displayed on the surface of target cells that are destroyed as the central component of autoimmune disease pathology.

To address this knowledge gap, we turned to type 1 diabetes (T1D), an organ-specific autoimmune disease focused on the islets of Langerhans, in which $\beta$-cells are destroyed, leading to lifelong insulin dependence. Recent genome wide association studies have highlighted a key role for MHCI genes in determining disease susceptibility ( $H L A A * 02$, $H L A A^{*} 11, H L A A^{*} 24$ and $\left.H L A B^{*} 39\right)^{1}$ with a relative risk comparable to, or greater than, more classically associated genes such as INS and PTPN22. As the major role of MHCI is to present peptide antigens to $\mathrm{CD} 8^{+}$cytotoxic $\mathrm{T}$ lymphocytes, there are sound reasons for proposing that $\mathrm{CD} 8^{+} \mathrm{T}$ cells specific for $\beta$-cell-derived peptides presented by $\mathrm{MHCI}$ molecules play a pivotal role in $\beta$-cell destruction. Indeed, $\mathrm{CD} 8^{+} \mathrm{T}$ cells dominate the characteristic islet mononuclear cell infiltrate observed post mortem in patients studied close to diagnosis ${ }^{18}$ and are required to mediate efficient adoptive transfer of disease in animal models ${ }^{19}$. As proof-of-concept, we recently generated a CD8 ${ }^{+} \mathrm{T}$ cell clone (1E6) specific for the major $\beta$-cell autoantigen, preproinsulin (PPI) using a blood sample obtained from a patient studied 3 months after the onset of T1D, diagnosed using criteria of the American Diabetes Association and including acute onset of symptoms, glycosuria, random plasma glucose of $>11.1 \mathrm{mmol} / 1$ and positivity for autoantibodies to glutamic acid decarboxylase-65. The 1E6 clone mediates $\beta$-cell-specific killing via recognition of a highly distinctive HLA $\mathrm{A}^{*} 0201$-presented signal peptide epitope ( $\left.\mathrm{PPI}_{15-24}\right)$ that exhibits glucose-dependent presentation on the surface of human $\beta$-cells ${ }^{20}$. The contact between the TCR of this clone and $\mathrm{pMHCI}$ on the $\beta$-cell surface is thus representative of a critical, disease-determining molecular interaction in a common human autoimmune disease.

Here, we present the structures of the TCR expressed by the $\mathrm{CD} 8^{+} \beta$-cell cytotoxic $\mathrm{T}$ cell clone 1E6, its cognate HLA A*0201-ALWGPDPAAA antigen (A2-ALW), and the 1E6-A2ALW complex. This first structure of an auto-reactive TCR-pMHCI complex furthers our 
understanding of how autoreactive $\mathrm{T}$ cells may escape into the periphery by revealing a novel mechanism for autoreactive TCR recognition of an MHCI-restricted self-antigen.

\section{RESULTS}

\section{E6 T cells kill human islet cells with high sensitivity}

To consolidate the role of 1E6 T cells in T1D, we extended our previous studies ${ }^{20}$ on 1E6mediated killing, using human islet cells purified from a further three HLA A*0201 ${ }^{+}$organ donors. Previously, we reported robust killing when islet cells were pre-treated with cytokines as a means to increase HLA A*0201 surface expression ${ }^{20}$ thus recapitulating the well-described islet hyper-expression of MHCI that is seen in human T1D ${ }^{21}$ However, here we have shown that untreated islet cells with resting levels of MHCI expression, and without the addition of exogenous $\mathrm{PPI}_{15-24}$ peptide, are also highly sensitive to killing by $1 \mathrm{E} 6 \mathrm{~T}$ cells (Fig. 1). These data demonstrate that 1E6 T cells are capable of engaging with naturally occurring levels of pMHCI ligand (Supplementary Fig. 1) and can mediate disease-related effector functions as a consequence. Moreover, $\mathrm{CD} 8^{+} \mathrm{T}$ cells with specificity for this key $\beta$ cell target are enriched in the circulation of a majority of patients with T1D as shown by interferon- $\gamma$ (IFN- $\gamma$ ) ELISPOT studies ${ }^{20}$ and PPI 15 -24-loaded HLA A*0201 (A2-ALW)multimer staining of peripheral blood lymphocytes ${ }^{22}$, and show a preferential effector memory phenotype (data not shown). Thus, $\beta$-cell-reactive $\mathrm{CD} 8^{+} \mathrm{T}$ cells specific for A2ALW are likely to mediate important effector functions in T1D patients ${ }^{20}$.

\section{A central Gly-Pro-Asp motif governs $1 E 6$ T cell recognition}

Next, we probed the specificity of 1E6 T cells using a comprehensive peptide mutagenesis scan. The index (ALWGPDPAAA) sequence was used as a blueprint, and each residue was systematically mutated along the backbone with all remaining 19 amino acids. The production of tumor necrosis factor (TNF) was used as the activation readout. Using this approach, we found that the 1E6 TCR was tolerant to changes in peptide residues Ala1, Leu2, Ala8, Ala9, Ala10; in some cases, amino acid substitutions at these residues generated larger responses compared with the index peptide (e.g. Ala1 to Arg1, and Leu2 to Gln2) (Fig. 2). Anchor residue modifications can directly alter TCR binding affinity and T cell sensitivity ${ }^{23}$ thus the enhanced responses observed could reflect, at least in part, indirect modifications to the conformation of the peptide that aid TCR binding. In contrast, modifications to the central Gly-Pro-Asp-Pro motif were not well tolerated. Modifications to this region of the peptide reduced activation by at least half in all instances, whereas changes to other regions of the peptide were substantially less critical, and in some cases increased activation compared to the wildtype sequence. This is consistent with previous structural data showing that TCRs generally focus on the central residues of the peptide, which typically bulge out of the $\mathrm{MHC}$ groove $\mathrm{e}^{4,15}$. Overall, the functional mutagenesis scan demonstrated the critical importance of the central Gly-Pro-Asp motif in peptide recognition by the $1 \mathrm{E} 6 \mathrm{CD}^{+} \mathrm{T}$ cell clone.

\section{The 1E6 TCR binds very weakly to A2-ALW}

We next determined the affinity of the 1E6-A2-ALW interaction using surface plasmon resonance (SPR). Typically, the affinity of a pathogen-specific TCR-pMHCI interaction lies in the region of 1-10 $\mu \mathrm{M}^{24}$. In contrast, the binding affinity of the 1E6-A2-ALW interaction was very low $\left(\mathrm{K}_{\mathrm{D}} \approx 278 \mu \mathrm{M} \pm 7.6 \mu \mathrm{M}\right.$ at $\left.25^{\circ} \mathrm{C}\right)$, with kinetics that were too rapid to measure (Table 1, Supplementary Fig. 2). In order to confirm that this weak interaction was not temperature-dependent, we also measured the binding affinity at $5^{\circ} \mathrm{C}\left(\mathrm{K}_{\mathrm{D}} \approx 274.5 \mu \mathrm{M}\right)$ and $37^{\circ} \mathrm{C}\left(\mathrm{K}_{\mathrm{D}} \approx 335 \mu \mathrm{M}\right)$, the latter reflecting physiological conditions (Table 1). Thus, similar to some other self-TCR-pMHCII interactions ${ }^{17,24}$, the affinity of this MHCI-restricted autoreactive TCR was very low and within the overall spectrum of TCR-pMHCI 
interactions for which biophysical data are available. Indeed, to the best of our knowledge, this is the lowest TCR-pMHC affinity recorded for any natural human agonist ligand.

\section{The $1 E 6$ TCR binds PMHC in a canonical orientation}

To investigate the structural basis of a $\mathrm{CD} 8^{+} \mathrm{T}$ cell response to an HLA A*0201-restricted, preproinsulin-derived epitope, we solved the structure of the 1E6 TCR in complex with A2ALW in two different crystal forms at 2.6 and $2.7 \AA$ resolution (Supplementary Table 1). The ternary complexes were virtually identical in the two different crystal forms, and thus the analysis was restricted to the complex solved at higher resolution. The electron density at the interface was unambiguous, permitting structural analysis to be undertaken (Supplementary Fig. 3). Further, we solved the structure of the binary A2-ALW complex and the uncomplexed 1E6 TCR to 1.7 and $2.6 \AA$, respectively (Supplementary Table 1), enabling assessment of the degree of conformational change that took place upon complex formation. Indeed, while plasticity of either the TCR and/or the peptide is a hallmark of the TCRpMHC interaction ${ }^{8}, 12,25,26$, neither the 1E6 TCR nor the A2-ALW complex moved appreciably during ligation. This indicated that the 1E6 autoreactive TCR engaged the pMHCI in a rigid 'lock and key' manner (Supplementary Fig. 4, 5).

Contrary to reports that some autoimmune TCRs bind to pMHC with atypical docking modes $^{13}, 16,17$, the 1E6 TCR bound in a conventional, centrally-located orientation, with the TCR $a$-chain positioned over the a2-helix and the TCR $\beta$-chain positioned over the a 1helix of the MHCI (Fig. 3a). Indeed, the 58.4 $4^{\circ}$ TCR docking angle (calculated as in ${ }^{4}$ ) for the 1E6-A2-ALW complex was within the range observed for other human pathogen-specific TCR-pMHC complexes $\left(32^{\circ}-80^{\circ}\right)$, with the 1E6 TCR being located over the solvent exposed Gly-Pro-Asp bulge of the ALW peptide (Fig. 3a and Fig.3b). The surface complementarity (SC) index across the interface was 0.61 , which also falls within the normal range for TCR-pMHCI complexes $(0.60-0.72)^{11}$. Further, the total buried surface area (BSA) of the 1E6-A2-ALW complex was $1640 \AA^{2}$, which falls at the lower end of the range observed for human TCR-pMHCI complexes (1470-2450 $\AA^{2}$ ). Thus, the 1E6-A2ALW complex exhibits overall characteristics typical of most previously determined TCRpMHCI structures.

\section{E6 TCR recognition involves limited MHC contacts}

Although in most TCR-pMHC structures solved to date the number of TCR contacts with peptide is less than the number of contacts with the restricting MHC molecule ${ }^{4}$, the 1E6-A2ALW interaction was unusually peptide-centric (see below) with a limited MHC contact footprint compared to other anti-pathogen TCR-pMHCI complex structures. For example, the crystal structure of the AS01 TCR in complex with an HLA-A*0201 restricted, Epstein Barr virus derived, antigen (A2-CLG) ${ }^{11}$, demonstrated far broader TCR interactions with both the MHC surface and the peptide (Fig. 3c and Fig. 3d). On average, human TCRs make $\sim 4$ H-bonds and $\sim 66$ Van der Waals (vdW) contacts with the MHC surface ${ }^{4}$. A TCR bound to a super-bulged 13-mer peptide made the fewest contacts with MHC seen to date ${ }^{4}$, with only $2 \mathrm{H}$-bonds, 1 salt-bridge and $36 \mathrm{vdW}$ contacts with the MHC (calculated independently using $\leq 4 \AA$ cut-off for vdW and $33.4 \AA$ cut-off for H-bonds and salt bridges ${ }^{27}$. In comparison, the 1E6 TCR formed only $2 \mathrm{H}$-bonds and $24 \mathrm{vdW}$ contacts with MHC (Table 2 ). At the interface, only the CDR3a loop interacted with the MHC surface, whereas both the CDR $2 \beta$ and CDR3 $\beta$ loops made MHC contacts (Fig. 4a). The CDR3 $a$ loop utilized; Asp94 to make 1 salt bridge and $2 \mathrm{vdW}$ contacts with MHC residue Lys66, Ser95a to make $1 \mathrm{H}$-bond and $1 \mathrm{vdW}$ with Arg65 and a solitary vdW with Lys66, and Ser96a to make 3 vdW with Arg65 (Table 2; Fig. 4b and Fig. 4c). Trp97 $\beta$ from the CDR3 $\beta$ loop made a network of $2 \mathrm{vdW}$ contacts each with MHC residues Ala150 and Val152. In addition, there was $1 \mathrm{vdW}$ contact between Ala101 $\beta$ and MHC residue Gln155, and $3 \mathrm{vdW}$ contacts 
between Lys102 $\beta$ and MHC residue His151 (Table 2; Fig. 4b and Fig. 4c). The TCR CDR2 $\beta$ loop contacted the MHC through a total of $9 \mathrm{vdW}$ interactions, comprising; $1 \mathrm{vdW}$ between Asn50 $\beta$ and Gln72, $1 \mathrm{vdW}$ between Asn51 $\beta$ and Val76, $3 \mathrm{vdW}$ between Val53 $\beta$ and Gln72, 2 vdW between Ile55 $\beta$ and Arg65, and 2 vdW between Asp56 $\beta$ and Arg65. The prominent role of the CDR3 loops, especially the CDR3a loop, in contacting the MHC contrasts with the current view that the germline encoded CDR1 and CDR2 loops govern interactions with the $\mathrm{MHC}^{28,29}$.

Previous TCR-pMHC structural analyses have unearthed the existence of three conserved MHC contact points (positions 65, 69 and 155; the "restriction triad") 27 , although the dependency of these positions in mediating TCR recognition is not absolute ${ }^{4}$. Of the nine MHC residues that were contacted by the TCR, Arg65 made a sizeable network of interactions with both the TCR $a$ and $\beta$ chains. However, although Arg65 was a chief MHC residue contacted by the 1E6 TCR, only $1(>3.4 \AA$ ) vdW contact was formed with the MHC 'gatekeeper' residue Gln155, and no contacts were made with the other restriction triad residue, Arg69. This suggests that, for this autoreactive TCR-pMHCI complex, contacting the conserved "triad" was not obligatory for productive engagement ${ }^{30}$.

\section{Focused peptide-centric recognition}

In contrast to typical TCR recognition of MHC molecules bound to $8-10$ mer peptides ${ }^{4}$, the 1E6 TCR formed a large number of peptide-mediated contacts compared to the MHC interactions. Specifically, 6/8 (75\%) of the H-bonds and salt bridges, and 53/77 (69\%) of the $\mathrm{vdW}$ contacts, were between the TCR and the peptide (Table 2). The TCR a-chain used only its CDR $3 a$ loop to contact the peptide, forming a total of $2 \mathrm{H}$-bonds and $32 \mathrm{vdW}$ contacts, while the TCR $\beta$-chain bound the peptide via its CDR1 $\beta$ and CDR3 $\beta$ loops, forming a total of $4 \mathrm{H}$-bonds and $21 \mathrm{vdW}$ contacts. The central positioning of the 1E6 TCR over the ALWGPDPAAA peptide enabled contacts with the central 5 amino acids of the peptide (GPDPA) (Fig. 5a and Fig. 5b). The TCR CDR3 $a$ and CDR3 $\beta$ loops formed a tight binding pocket around the GPDPA motif and accounted for the majority of the peptide contacts, whereas the CDR1 $\beta$ loop played a lesser role during peptide binding (Fig. 5b). While the 1E6 TCR was positioned in a canonical diagonal fashion over A2-ALW (Fig. 3a), the CDR3 loops of the 1E6 TCR were twisted into a perpendicular orientation over the peptide, enabling a greater number of TCR contacts to be formed with Pro5 (Fig. 3b). Although the 1E6 TCR interacted with 50\% of the residues in the peptide, most of the interactions were focused in a contact zone that included just 2 residues; Pro5 and Asp6. Indeed, Pro5 and Asp6 accounted for 4/6 of the H-bonds and 34/53 of the vdW contacts between the TCR and the peptide (Table 2; Fig. 5c and Fig. 5d). Pro5 formed $1 \mathrm{H}$-bond with TCR residue Asp94a and an important network of $23 \mathrm{vdW}$ interactions with Arg92a, Asp94a, Ser95a and Tyr97a within the TCR CDR3a loop (Fig. 5c). Asp6 formed $1 \mathrm{H}-$ bond and $5 \mathrm{vdW}$ contacts with Tyr97a in the TCR CDR3a loop, as well $1 \mathrm{H}$-bond and 2 vdW contacts with Tyr30 $\beta$ (CDR1 $\beta$ ), and $1 \mathrm{H}$-bond and $4 \mathrm{vdW}$ contacts with Trp97 $\beta$ (CDR3 $\beta$ ) (Fig. 5d). The structural importance of peptide residues Pro5 and Asp6 is consistent with the mutagenesis data (Fig. 2). Thus, the 1E6 TCR is highly focused upon a minimal peptide motif dominated by peptide residues Pro5 and Asp6.

\section{Two CDR3 residues dominate TCR contacts}

The dominant role of peptide residues Pro5 and Asp6 during TCR binding was mirrored by the dominant role of two contact residues in the 1E6 TCR in which Tyr97a and Trp97 $\beta$ from the CDR $3 a$ and CDR3 $\beta$ loops, respectively, dominated the interface (Table 2) and sat directly over the central Gly-Pro-Asp motif of the peptide (Fig. 5b-5d). Every pMHC contact made between the 1E6 TCR a-chain, and A2-ALW occurred via a germlineencoded residue (Table 2). Indeed, the 11-residue long 1E6 CDR3a loop was heavily 
germline-encoded with only $3 \mathrm{~N}$-nucleotide insertions encoding for Gly93. The two CDR3a contact residues, Asp94 and Tyr97, were encoded by the TRAV12-3 gene and the TRAJ12 junctional region gene, respectively. The longer than average 14-residue CDR3 $\beta$ loop enabled the formation of a two-turn a-helix, a secondary structure not previously seen in TCR CDR loops ${ }^{4}$. This unusual a-helix presented the Trp97 side chain in the correct orientation to make H-bonds with Asp6, stack its aromatic ring against Pro7 and Ala8, and make contacts with residues on the MHC a2-helix. The fact that Trp97 was the only residue in the CDR3 $\beta$ loop to contact the peptide underscores the importance of this residue in the recognition of A2-ALW (Table 2; Fig. 5d). The CDR3 $\beta$ loop was constructed from the TRBV12-4, TRBD2-2 and TRBJ2-4 genes, with six N-nucleotide insertions encoding Trp97, Lys99 and Leu100. Trp is rarely found in CDR3 loops as it is not encoded in the junctional region of any of the 47 TRAV genes or 54 TRBV genes. Trp is found in just one of 57 TRAJ junctional regions (TRAJ34) and does not occur in any of the 13 TRBJ genes. Furthermore, Trp is also one of just two amino acids encoded by only one of the 64 genetic codons. Thus, the manufacture of CDR3 loops including Trp is statistically less probable during V(D)J recombination. Overall, when considering TCR germline coding regions and $\mathrm{N}$-nucleotide encoding, Trp is the rarest amino acid in CDR3 loops. Further, prominently surface exposed Trp residues are often a signature for mediating protein-protein interactions ${ }^{31}$. Thus, Trp97 $\beta$ alongside Tyr97a is ideally suited to form a receptor-binding interface; indeed, this combination of residues formed an 'aromatic cap' that dominated TCR contacts with the A2-ALW complex. These highly focused interactions between just two TCR residues and two peptide residues governed the antigen specificity of the 1E6 TCR.

\section{DISCUSSION}

Despite mounting evidence that MHCI-restricted $\mathrm{CD} 8^{+} \mathrm{T}$ cells play a pivotal role in the development of T1D, the structural and biophysical basis for such an interaction with target $\beta$-cells has not been studied. To investigate the molecular basis for the recognition of an HLA A*0201-restricted preproinsulin epitope (A2-ALW) by a CD8 ${ }^{+} \mathrm{T}$ cell clone, we solved the structures of the autoreactive 1E6 TCR and A2-ALW in isolation and in complex. Overall, the 1E6 TCR bound to A2-ALW in a canonical diagonal fashion, with the CDR3 loops positioned over the central bulge of the peptide. Nevertheless, despite this standard docking orientation, the 1E6 TCR engaged A2-ALW with an extremely low affinity, attributable to a lower than average BSA and limited MHC contact footprint. Further, several other features of the complex are noteworthy. In contrast to most TCR-pMHC structures determined to date, this autoreactive TCR-pMHCI interaction was characterized by a rigid 'lock and key' conformation that is more typical of innate receptors or natural killer T cell TCR-CD1d-Antigen interactions ${ }^{32,33}$. Moreover, the interaction was dominated by the CDR3 loops, consistent with a previously proposed system in which non-germlineencoded CDR3 loops drive the energetic landscape of recognition ${ }^{34}$, and yet conflicting with current theories regarding the role of the CDR1 and CDR2 loops as determinants of MHCrestriction $28,29,35,36$. Our findings, that $\mathrm{T}$ cells specific for this antigen are highly enriched in T1D patients ${ }^{20,22}$, and that $1 \mathrm{E} 6 \mathrm{~T}$ cells kill resting $\beta$-cells in vitro, suggest that ultra-low affinity binding and highly limited MHC footprint are still sufficient to have an important impact on the destructive processes that lead to insulin deficiency and T1D.

Unusually, the 1E6-A2-ALW interaction was predominantly focused through just two aromatic TCR residues, with Tyr97 $\alpha$ and Trp97 $\beta$ accounting for $64 \%$ of the contacts. Residue-focused binding was mirrored by the peptide, in which just 2/5 TCR contact residues (Pro5 and Asp6) comprised 63\% of the contacts. Thus, the interaction between the 1E6 TCR and the ALW peptide was exquisitely focused and governed by a binding mechanism dominated by just two TCR and two peptide residues. Aromatic residues, and 
surface exposed Trp residues in particular, commonly participate in protein-protein interactions ${ }^{31}$, yet are relatively rare in TCR CDR3 loops. Nonetheless, Tyr97a and Trp97 $\beta$ appeared to be the driving force in this otherwise weak TCR-pMHCI interaction, acting as an aromatic cap that perches on a central region of the peptide.

There is considerable interest as to how $\mathrm{T}$ cells bearing TCRs that interact with autoantigens escape negative selection in the thymus and populate the periphery. Comparison of 1E6-A2ALW and four other self-reactive human TCR-pMHC complexes with a typical HLA $A^{*} 0201$ pathogen-reactive complex highlights some of the differences in TCR binding to autoimmune and microbial antigens observed to date. These differences suggest several possible mechanisms to explain how self-reactive $\mathrm{T}$ cells might escape negative selection. First, a DR4-MBP-specific TCR was shown to bind cognate antigen with high affinity and normal topology ${ }^{14}$. This is the strongest TCR affinity reported to date for any MHCIIrestricted antigen, and lies in the range reported for pathogen-specific MHCI-restricted $\mathrm{TCRs}^{24}$. However, the DR4-MBP epitope was highly unstable, leading to the hypothesis that $\mathrm{T}$ cells responding to low antigen densities in the thymus could receive a weak signal for positive selection, but then activate in response to higher antigen densities in the periphery. Second, self-reactive TCR-pMHC complexes, such as Ob.1A12-DR2a-MBP, 3A6-DR2-MBP and hy.1B11-DQ-MBP, were found to exhibit unusual conformations compared to more conventional pathogen-specific TCR-pMHC interactions ${ }^{13,16,17}$. Such unusual TCR-pMHC binding orientations may allow T cells bearing these TCRs to bypass negative selection signals. Our own findings suggest a third route of thymic escape. The 1E6 TCR bound A2-ALW conventionally, but with a very low affinity that was highly peptidecentric. The low affinity of 1E6 TCR may be below the threshold required to induce negative selection but is sufficient to induce killing of $\beta$-cells ${ }^{20}$. It is tempting to speculate that, for this TCR at least, the presence of cognate pMHCI in the thymus is highly determining with regard to selection. It is noteworthy that the INS gene encoding PPI is transcribed and translated in the thymus and that possession of variable numbers of tandem repeats of a consensus sequence located $5^{\prime}$ of the coding region is the strongest genetic risk for T1D outside the $\mathrm{MHC}^{37}$. Homozygosity for alleles containing few repeats (AA at rs689) confers a $>2$-fold relative risk of disease and is associated with 2-3 fold-reduced thymic transcription level compared with homozygous protection (TT at rs689) ${ }^{38}$. It is proposed that reduced thymic INS expression impairs central tolerance to PPI and this paradigm is supported by the demonstration that non-obese diabetic mice with targeted deletion of INS 2 (syntenic to human INS) display enhanced T cell reactivity to insulin and more rapid and penetrant disease ${ }^{39}$. The T1D patient from whom 1E6 was obtained has AA at rs689. Notably, all three of the above mechanisms represent atypical recognition parameters that may help self-reactive $\mathrm{T}$ cells to bypass thymic deletion.

The observation that clone 1E6 has the lowest TCR affinity for pMHC described to date, yet remains able to kill resting human HLA-A*0201 $\beta$-cells expressing low levels of HLA class $\mathrm{I}$, is a further potentially important observation in relation to disease pathogenesis, since it suggests that such clones have the potential to engage non-conditioned targets. Most disease models of T1D pathogenesis and initiation elaborated to date argue that islet inflammation comes first, and that the resulting cytokine-induced islet hyper-expression of HLA class I facilitates $\mathrm{CD} 8^{+} \mathrm{T}$ cell killing. Our data raise the possibility that $\mathrm{CD} 8^{+} \mathrm{T}$ cell killing could be an early event. Pre-existing low affinity $\mathrm{CD} 8^{+} \mathrm{T}$ cells could also be relevant in the setting of islet transplantation, in which donor $\beta$-cells express resting levels of HLA class I and therefore constitute targets for 1E6-like $\mathrm{CD}^{+} \mathrm{T}$ cells. Similarly, the future use of genemodified $\beta$-cell replacement therapy may need to include designs that limit HLA class I expression to avoid disease recurrence. Finally, our observations raise the important consideration as to whether 1E6-like autoreactive T cells with ultra-low affinity TCRs are originally primed by self- or non-self ligands. We consider that our findings make the latter 
more likely, especially when viewed in the context of numerous studies implying a link between viruses, islet autoimmunity and T1D. Extensive searching of databases of viral proteins against ALWGPDPAAA, or modifications tolerated by 1E6 TCR, followed by examination of stimulation of 1E6 in vitro have not to date revealed any potential virusderived ligands (data not shown). However, the number of complete sequences of viruses that might be considered of highest relevance (eg the human enteroviruses), and are in the public domain, are currently limited and pathogen cross-reactivity will remain an important question to be that needs to be addressed. We have recently shown that the $1 \mathrm{E} 6$ clone recognizes over a million distinct decamer peptides in the context HLA $A^{*} 0201^{40}$. A large number of peptides acted as substantially better agonists than the preproinsulin-derived peptide ALWGPDPAAA with the most potent peptide identified, RQFGPDFPTI, differing from this 'index' sequence at 7 of 10 amino acids. These findings serve to highlight the enormous potential of TCR degeneracy to be a causative factor in autoimmune disease.

In summary, we present the first structure of a human TCR in complex with an autoreactive MHCI-restricted antigen. Collectively, our observations suggest that $\mathrm{CD} 8^{+} \mathrm{T}$ cells expressing the 1E6 TCR could evade negative selection due to a 'light-touch' MHC contact footprint and weak TCR binding. In the periphery, $\beta$-cells operating in the presence of elevated glucose levels, combined with the pro-inflammatory milieu that leads to hyperexpression of MHCI, might drive high levels of surface A2-ALW expression and render these cells susceptible to antigen-experienced, 1E6-like $\mathrm{CD}^{+} \mathrm{T}$ cells ${ }^{20,41}$. Such $\mathrm{T}$ cells with low avidity for self likely require priming through contact with an infectious agent. It is possible that the unusual features of 1E6 TCR binding, focusing on just two residues in the peptide, as seen here, might increase the chances of pathogen-derived peptide crossrecognition. Indeed, it has been speculated that such 'hotspot mimicry' limited to a small number of key features within the TCR-binding footprint could contribute to the initiation of multiple sclerosis ${ }^{42}$. Collectively, these data suggest a mechanism by which 1E6-like CD8 ${ }^{+}$ $\mathrm{T}$ cells avoid thymic culling to populate the periphery and cause disease.

\section{Methods \\ Cytoxicity assays}

Human islet cells were isolated as described previously ${ }^{43}$. Pancreata were retrieved with the consent of donors' relatives and permission from the Ethical Review Committee of King's College Hospital. Islet-enriched cell fractions were cultured in CMRL1066 containing 5.6 $\mathrm{mM}$ glucose, supplemented with $10 \%$ fetal bovine serum (FBS), penicillin $(100 \mathrm{U} / \mathrm{ml})$, streptomycin $(100 \mu \mathrm{g} / \mathrm{ml})$ and L-glutamine $(2 \mathrm{mM})$ (Invitrogen) for 2 weeks. Cells were allowed to become monolayer cultures and were cultured with $16 \mathrm{mM}$ glucose in either the presence or absence of IL-1 $\beta$ (50 IU $/ \mathrm{ml}$; Strathmann Biotec), TNF (2,500 IU /ml), IFN- $\gamma$ (500 IU/ml; Miltenyi Biotec) and IFN-a (1,000IU/ml; Roche Laboratories) for 16-24 hr to upregulate HLA class I expression. Cytotoxicity was analyzed using a non-radioactive Europium TDA (EuTDA) cytotoxicity assay with DELFIA® Technology (Perkin Elmer) according to the manufacturer's instructions. Briefly, human islet cells $\left(10^{6}\right)$ were incubated for $20 \mathrm{~min}$ at $37^{\circ} \mathrm{C}$ in $2 \mathrm{ml}$ of CMRL1066 (complete) with $3 \mu \mathrm{l}$ of fluorescence-enhancing ligand. After washing with PBS ( 3 times), $50 \mu$ l of labeled islets cells $\left(5 \times 10^{3}\right)$ were seeded in triplicate into V-shaped 96-well plates followed by $50 \mu \mathrm{l}$ of effector cells (CD8 ${ }^{+} \mathrm{T}$ cell clone) at varying ratios in X-Vivo 15/5\% AB serum containing IL-7 (10 ng/ml), IL-15 (0.1 $\mathrm{ng} / \mathrm{ml}$ ) and $2.5 \%$ Cellkines (Helvetica Healthcare). The cultures were incubated for $4 \mathrm{hr}$ at $37^{\circ} \mathrm{C}$, then $20 \mu \mathrm{l}$ of supernatant was transferred into a clear, flat-bottom microtitration plate followed by the addition of $200 \mu \mathrm{l} / \mathrm{well}$ of enhancement solution. After $15 \mathrm{~min}$ at room temperature with shaking, the europium signal was measured using a FLUOstar OMEGA ${ }^{\mathrm{TM}}$ Time-Resolved Fluorescence reader (BMG Labtech). To determine maximum lysis, islet cells alone $\left(5 \times 10^{3}\right.$ in $100 \mu$ l) were treated with $20 \mu 1$ lysis buffer. Spontaneous release was 
measured from wells containing only labeled islet cells in $100 \mu$ l medium. Specific cytotoxicity was calculated using the formula: $\%$ specific release $=($ experimentalspontaneous release $) \times 100 /($ maximum-spontaneous release $)$.

\section{Peptide mutagenesis scan of 1E6 T cells}

For the recognition screen, $2 \times 10^{3} 1 \mathrm{E} 6 \mathrm{CD} 8^{+} \mathrm{T}$ cells were cultured in triplicate for $16 \mathrm{hr}$ with individual peptides representing every positional variant $(n=190)$ of the wildtype PPI $15-24$ epitope sequence (ALWGPDPAAA) at a concentration of $1 \mu \mathrm{g} / \mathrm{ml}$. Supernatant was harvested and analyzed for TNF production by ELISA according to the manufacturer's instructions (Life Technologies, Paisley, UK).

\section{Generation of $\mathrm{CD8}^{+} \mathrm{T}$ cell clones and expression plasmids}

$\mathrm{CD}^{+} \mathrm{T}$ cell clones specific for A2-ALW were generated as described previously ${ }^{20}$. The $1 E 6$ TCR, HLA $A * 0201 \mathrm{a}$-chain and $\beta 2 \mathrm{~m}$ sequences were generated by PCR mutagenesis (Stratagene) and PCR cloning. For the 1E6 TCR, a disulphide linked construct was used to produce the soluble domains (variable and constant) for both the $a$ and $\beta$ chains ${ }^{44}$. The soluble HLA A*0201 a-chain ( $a 1, a 2$ and $a 3$ domains), tagged with a biotinylation sequence, and $\beta 2 \mathrm{~m}$ were also cloned and used to make the HLA A*0201 protein. The TCR $a$ and $\beta$ chains, HLA A*0201 $\alpha$-chain and $\beta 2 \mathrm{~m}$ sequences were inserted into separate pGMT7 expression plasmids under the control of the T7 promoter.

\section{Protein expression, refolding and purification}

Competent Rosetta DE3 E. coli cells were used to produce the 1E6 TCR $\alpha$ and $\beta$ chains, and the HLA A*0201 a-chain and $\beta 2 \mathrm{~m}$, in the form of inclusion bodies (IBs) using $0.5 \mathrm{mM}$ IPTG to induce expression as described previously ${ }^{44}$. TCR and pMHCI proteins were refolded as previously described ${ }^{24}$. Refolded proteins were purified initially by ion exchange using a Poros50HQ ${ }^{\mathrm{TM}}$ column and finally gel filtered into BIAcore buffer (10 mM HEPES pH 7.4, $150 \mathrm{mM} \mathrm{NaCl}, 3 \mathrm{mM}$ EDTA and $0.005 \%$ (v/v) Surfactant P20) or crystallization buffer $\left(10 \mathrm{mM}\right.$ TRIS pH 8.1,10mM NaCl) using a Superdex200HR ${ }^{\mathrm{TM}}$ column. Protein quality was analyzed by Coomassie-stained SDS-PAGE.

\section{pMHC biotinylation}

Biotinylated pMHC was prepared as described previously ${ }^{45}$.

\section{Surface plasmon resonance (SPR) analysis}

Binding analysis was performed using a BIAcore T100 ${ }^{\mathrm{TM}}$ equipped with a CM5 sensor chip as reported previously ${ }^{45}$. Briefly, between 200 and 400 response units (RUs) of biotinylated pMHC was immobilized to streptavidin, which was chemically linked to the chip surface. Equilibrium analysis was performed using ten serial dilutions, prepared in triplicate, for each sample and injected over the relevant sensor chips at $25^{\circ} \mathrm{C}$. The 1E6 TCR was injected over the chip surface using kinetic injections at a flow rate of $45 \mu 1 / \mathrm{min}$. To assess temperature dependency, this method was repeated at $5^{\circ} \mathrm{C}$ and $37^{\circ} \mathrm{C}$. Results were analyzed using BIAevaluation 3.1 $1^{\mathrm{TM}}$, Microsoft Excel ${ }^{\mathrm{TM}}$ and Origin 6.1 $1^{\mathrm{TM}}$. The equilibrium binding constant $\left(\mathrm{K}_{\mathrm{D}}\right)$ values were calculated using a nonlinear curve fit $\left(\mathrm{y}=\left(\mathrm{P}_{1} \mathrm{x}\right) /\left(\mathrm{P}_{2}+\mathrm{x}\right)\right)$.

\section{Crystallization, diffraction data collection and model refinement}

1E6-A2-ALW, 1E6 TCR and A2-ALW crystals were grown at $18^{\circ} \mathrm{C}$ by vapour diffusion via the sitting drop technique. For 1E6-A2-ALW, optimal crystals were obtained with $0.2 \mathrm{M}$ sodium citrate, $0.1 \mathrm{M}$ Bis Tris propane $\mathrm{pH} 6.5,20 \% \mathrm{w} / \mathrm{v}$ polyethylene glycol (PEG) 3350. For A2-ALW, optimal crystals were obtained with $0.2 \mathrm{M}$ potassium/sodium tartrate, $0.1 \mathrm{M}$ Bis Tris propane, $\mathrm{pH}$ 6.5, $20 \%$ w/v PEG 3350. For 1E6 TCR, optimal crystals were obtained 
with $0.2 \mathrm{M}$ sodium iodide, $20 \%$ w/v PEG 3350. All crystals were soaked in 30\% ethylene glycol before cryo-cooling. All crystallization screens and optimization experiments were completed using an Art-Robbins Phoenix dispensing robot (Alpha Biotech Ltd, UK). Data were collected at $100 \mathrm{~K}$ at the Diamond Light Source (DLS), Oxfordshire, UK. All datasets were collected at a wavelength of $0.976 \AA$ using an ADSC Q315 CCD detector. Reflection intensities were estimated with the XIA2 package ${ }^{46}$ and the data were scaled, reduced and analyzed with SCALA and the CCP4 package ${ }^{47}$. The structure was solved with molecular replacement using $\mathrm{AMORE}^{48}$. The model sequence was adjusted with $\mathrm{COOT}^{49}$ and the model refined with REFMAC5. Graphical representations were prepared with PYMOL ${ }^{50}$. Data reduction and refinement statistics are shown in Supplementary Table 1.

\section{Supplementary Material}

Refer to Web version on PubMed Central for supplementary material.

\section{Acknowledgments}

We thank the staff at Diamond Light Source for providing facilities and support. This work was funded by the BBSRC (grant BB/H001085/1), the Wellcome Trust (WT086716 to AKS to WT095767 to DKC), the JDRF (7-2005-877 and 1-2007-1803 to MP; 17-2009-806 to AKS, MP, DAP and AS), EU FP7 (241447 NAIMIT) and NIHR cBRC at Guy's \& St Thomas' NHS Foundation Trust and King's College London. Fellowship support was received from RCUK (PJR), NHMRC (JR), WORD (JJM), MRC (DAP) and Wellcome Trust (LW). We are grateful to M Zhao for help preparing the human islets and John Todd for INS genotyping.

\section{Non-standard abbreviations}

pMHC peptide-major histocompatibility complex

RU response unit

SPR surface plasmon resonance

T1D type 1 diabetes

\section{References}

1. Nejentsev S, et al. Localization of type 1 diabetes susceptibility to the MHC class I genes HLA-B and HLA-A. Nature. 2007; 450:887-892. [PubMed: 18004301]

2. Wucherpfennig KW, Sethi D. T cell receptor recognition of self and foreign antigens in the induction of autoimmunity. Semin Immunol. 2011; 23:84-91. [PubMed: 21306912]

3. Kappler JW, Roehm N, Marrack P. T cell tolerance by clonal elimination in the thymus. Cell. 1987; 49:273-280. [PubMed: 3494522]

4. Rudolph MG, Stanfield RL, Wilson IA. How TCRs bind MHCs, peptides, and coreceptors. Annu Rev Immunol. 2006; 24:419-466. [PubMed: 16551255]

5. Colf LA, et al. How a single T cell receptor recognizes both self and foreign MHC. Cell. 2007; 129:135-146. [PubMed: 17418792]

6. Feng D, Bond CJ, Ely LK, Maynard J, Garcia KC. Structural evidence for a germline-encoded T cell receptor-major histocompatibility complex interaction 'codon'. Nat Immunol. 2007; 8:975-983. [PubMed: 17694060]

7. Sami M, et al. Crystal structures of high affinity human T-cell receptors bound to peptide major histocompatibility complex reveal native diagonal binding geometry. Protein Eng Des Sel. 2007; 20:397-403. [PubMed: 17644531]

8. Borbulevych OY, et al. T cell receptor cross-reactivity directed by antigen-dependent tuning of peptide-MHC molecular flexibility. Immunity. 2009; 31:885-896. [PubMed: 20064447]

9. Cole DK, et al. Germ line-governed recognition of a cancer epitope by an immunodominant human T-cell receptor. J Biol Chem. 2009; 284:27281-27289. [PubMed: 19605354] 
10. Gras S, et al. Structural bases for the affinity-driven selection of a public TCR against a dominant human cytomegalovirus epitope. J Immunol. 2009; 183:430-437. [PubMed: 19542454]

11. Miles JJ, et al. Genetic and structural basis for selection of a ubiquitous T cell receptor deployed in epstein-barr virus infection. PLoS Pathog. 2010; 6:e1001198. [PubMed: 21124993]

12. Borbulevych OY, Piepenbrink KH, Baker BM. Conformational melding permits a conserved binding geometry in TCR recognition of foreign and self molecular mimics. J Immunol. 2011; 186:2950-2958. [PubMed: 21282516]

13. Sethi DK, et al. A highly tilted binding mode by a self-reactive $\mathrm{T}$ cell receptor results in altered engagement of peptide and MHC. J Exp Med. 2011; 208:91-102. [PubMed: 21199956]

14. Yin Y, Li Y, Kerzic MC, Martin R, Mariuzza RA. Structure of a TCR with high affinity for selfantigen reveals basis for escape from negative selection. EMBO J. 2011; 30:1137-1148. [PubMed: 21297580]

15. Godfrey DI, Rossjohn J, McCluskey J. The fidelity, occasional promiscuity, and versatility of T cell receptor recognition. Immunity. 2008; 28:304-314. [PubMed: 18342005]

16. Hahn M, Nicholson MJ, Pyrdol J, Wucherpfennig KW. Unconventional topology of self peptidemajor histocompatibility complex binding by a human autoimmune $\mathrm{T}$ cell receptor. Nat Immunol. 2005; 6:490-496. [PubMed: 15821740]

17. Li Y, et al. Structure of a human autoimmune TCR bound to a myelin basic protein self-peptide and a multiple sclerosis-associated MHC class II molecule. EMBO J. 2005; 24:2968-2979. [PubMed: 16079912]

18. Willcox A, Richardson SJ, Bone AJ, Foulis AK, Morgan NG. Analysis of islet inflammation in human type 1 diabetes. Clin Exp Immunol. 2009; 155:173-181. [PubMed: 19128359]

19. DiLorenzo TP, Serreze DV. The good turned ugly: immunopathogenic basis for diabetogenic CD8+ T cells in NOD mice. Immunol Rev. 2005; 204:250-263. [PubMed: 15790363]

20. Skowera A, et al. CTLs are targeted to kill beta cells in patients with type 1 diabetes through recognition of a glucose-regulated preproinsulin epitope. J Clin Invest. 2008; 118:3390-3402. [PubMed: 18802479]

21. Foulis AK, Farquharson MA, Meager A. Immunoreactive alpha-interferon in insulin-secreting beta cells in type 1 diabetes mellitus. Lancet. 1987; 2:1423-1427. [PubMed: 2891993]

22. Velthuis JH, et al. Simultaneous detection of circulating autoreactive CD8+ T-cells specific for different islet cell-associated epitopes using combinatorial MHC multimers. Diabetes. 2010; 59:1721-1730. [PubMed: 20357361]

23. Cole DK, et al. Modification of MHC anchor residues generates heteroclitic peptides that alter TCR binding and T cell recognition. J Immunol. 2010; 185:2600-2610. [PubMed: 20639478]

24. Cole DK, et al. Human TCR-Binding Affinity is Governed by MHC Class Restriction. J Immunol. 2007; 178:5727-5734. [PubMed: 17442956]

25. Armstrong KM, Piepenbrink KH, Baker BM. Conformational changes and flexibility in T-cell receptor recognition of peptide-MHC complexes. Biochem J. 2008; 415:183-196. [PubMed: 18800968]

26. Tynan FE, et al. A T cell receptor flattens a bulged antigenic peptide presented by a major histocompatibility complex class I molecule. Nat Immunol. 2007; 8:268-276. [PubMed: 17259989]

27. Tynan FE, et al. T cell receptor recognition of a 'super-bulged' major histocompatibility complex class I-bound peptide. Nat Immunol. 2005; 6:1114-1122. [PubMed: 16186824]

28. Dai S, et al. Crossreactive T Cells spotlight the germline rules for alphabeta T cell-receptor interactions with MHC molecules. Immunity. 2008; 28:324-334. [PubMed: 18308592]

29. Wu LC, Tuot DS, Lyons DS, Garcia KC, Davis MM. Two-step binding mechanism for T-cell receptor recognition of peptide MHC. Nature. 2002; 418:552-556. [PubMed: 12152083]

30. Burrows SR, et al. Hard wiring of T cell receptor specificity for the major histocompatibility complex is underpinned by TCR adaptability. Proc Natl Acad Sci U S A. 2010; 107:10608-10613. [PubMed: 20483993]

31. Pang SS, et al. The structural basis for autonomous dimerization of the pre-T-cell antigen receptor. Nature. 2010; 467:844-848. [PubMed: 20944746] 
32. Borg NA, et al. CD1d-lipid-antigen recognition by the semi-invariant NKT T-cell receptor. Nature. 2007; 448:44-49. [PubMed: 17581592]

33. Godfrey DI, et al. Antigen recognition by CD1d-restricted NKT T cell receptors. Semin Immunol. 2010; 22:61-67. [PubMed: 19945889]

34. Borg NA, et al. The CDR3 regions of an immunodominant $\mathrm{T}$ cell receptor dictate the 'energetic landscape' of peptide-MHC recognition. Nat Immunol. 2005; 6:171-180. [PubMed: 15640805]

35. Garcia KC, Adams JJ, Feng D, Ely LK. The molecular basis of TCR germline bias for MHC is surprisingly simple. Nat Immunol. 2009; 10:143-147. [PubMed: 19148199]

36. Scott-Browne JP, White J, Kappler JW, Gapin L, Marrack P. Germline-encoded amino acids in the alphabeta T-cell receptor control thymic selection. Nature. 2009; 458:1043-1046. [PubMed: 19262510]

37. Todd JA, et al. Robust associations of four new chromosome regions from genome-wide analyses of type 1 diabetes. Nat Genet. 2007; 39:857-864. [PubMed: 17554260]

38. Pugliese A, et al. The insulin gene is transcribed in the human thymus and transcription levels correlated with allelic variation at the INS VNTR-IDDM2 susceptibility locus for type 1 diabetes. Nat Genet. 1997; 15:293-297. [PubMed: 9054945]

39. Thebault-Baumont K, et al. Acceleration of type 1 diabetes mellitus in proinsulin 2-deficient NOD mice. J Clin Invest. 2003; 111:851-857. [PubMed: 12639991]

40. Wooldridge L, et al. A single autoimmune T-cell receptor recognizes over a million different peptides. J Biol Chem. 2011 doi:10.1074/jbc.M1111.289488.

41. Foulis AK, Farquharson MA, Hardman R. Aberrant expression of class II major histocompatibility complex molecules by B cells and hyperexpression of class I major histocompatibility complex molecules by insulin containing islets in type 1 (insulin-dependent) diabetes mellitus. Diabetologia. 1987; 30:333-343. [PubMed: 3301484]

42. Harkiolaki M, et al. T cell-mediated autoimmune disease due to low-affinity crossreactivity to common microbial peptides. Immunity. 2009; 30:348-357. [PubMed: 19303388]

\section{Online Methods References}

43. Huang GC, et al. The development of new density gradient media for purifying human islets and islet-quality assessments. Transplantation. 2004; 77:143-145. [PubMed: 14724452]

44. Boulter JM, et al. Stable, soluble T-cell receptor molecules for crystallization and therapeutics. Protein Eng. 2003; 16:707-711. [PubMed: 14560057]

45. Cole DK, et al. T cell receptor engagement of peptide-major histocompatibility complex class I does not modify CD8 binding. Mol Immunol. 2008; 45:2700-2709. [PubMed: 18243322]

46. Winter G. xia2: an expert system for macromolecular crystallography data reduction. Journal of Applied Crystallography. 2010; 43:186-190.

47. Collaborative Computational Project, N. The CCP4 suite: programs for protein crystallography. Acta Crystallogr D Biol Crystallogr. 1994; 50:760-763. [PubMed: 15299374]

48. Trapani S, Navaza J. AMoRe: classical and modern. Acta Crystallogr D Biol Crystallogr. 2008; 64:11-16. [PubMed: 18094462]

49. Emsley P, Cowtan K. Coot: model-building tools for molecular graphics. Acta Crystallogr D Biol Crystallogr. 2004; 60:2126-2132. [PubMed: 15572765]

50. Delano, WL. The PyMOL Molecular Graphics System. DeLano Scientific; San Carlos, CA, USA: 2002. 


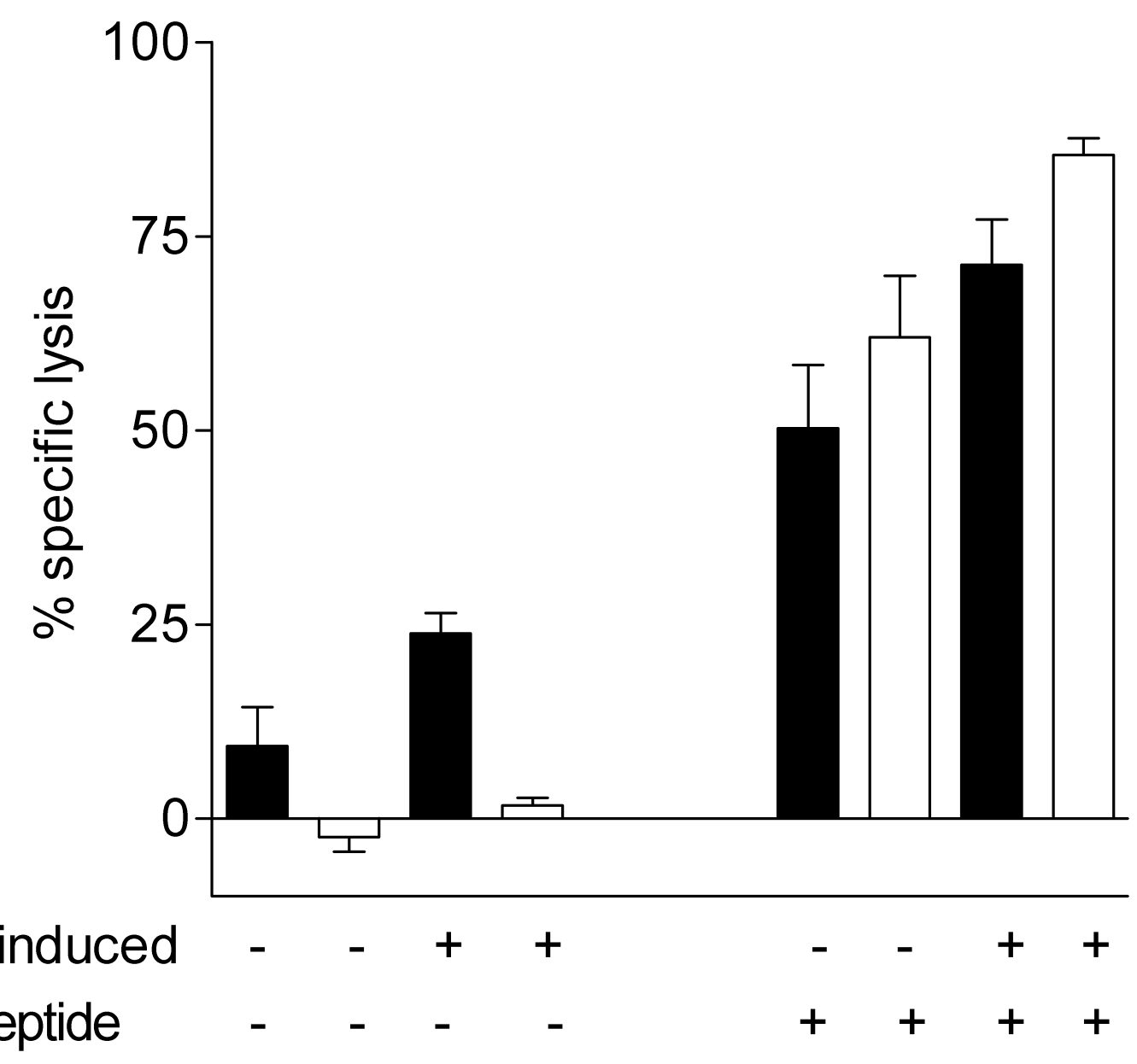

Figure 1.

The PPI $15-24$-specific HLA A* $0201^{+}$-restricted CD8 ${ }^{+}$T cell clone, $1 \mathrm{E} 6$, kills unmanipulated human islets from multiple donors without any requirement for cytokine treatment or addition of exogenous cognate peptide. Percent specific lysis of human islet cells cocultured with 1E6 (black bars) or a CD8 ${ }^{+} \mathrm{T}$ cell clone specific for the CMV pp65 $495-503$ peptide (white bars). Bars represent mean values \pm SEM of accumulated data from 3 triplicate studies carried out using 3 different HLA A* $0201^{+}$organ donors. Clear killing by $1 \mathrm{E} 6$ is observed in the absence of cytokine treatment; this is enhanced when islets are pretreated with cytokines to induce HLA class I expression (Supplementary Fig. 1). Parallel control experiments conducted in the presence of exogenous cognate peptide are also shown for both $\mathrm{CD} 8^{+} \mathrm{T}$ cell clones. 


\begin{tabular}{|c|c|c|c|c|c|c|c|c|c|c|}
\hline Index & A & L & W & G & P & D & P & A & A & A \\
\hline & Position 1 & Position 2 & Position 3 & Position 4 & Position 5 & Position 6 & Position 7 & Position 8 & Position 9 & Position 10 \\
\hline A & 100 & 133 & 48 & 51 & 17 & 35 & 24 & 100 & 100 & 100 \\
\hline F & 37 & 9 & 16 & 19 & 19 & 0 & 10 & 0 & 65 & 1 \\
\hline I & 126 & 80 & 22 & 39 & 15 & 0 & 24 & 79 & 45 & 74 \\
\hline L & 29 & 100 & 14 & 30 & 7 & 0 & 18 & 135 & 18 & 224 \\
\hline M & 44 & 207 & 10 & 34 & 24 & 16 & 0 & 132 & 99 & 32 \\
\hline P & 41 & 0 & 45 & 34 & 100 & 14 & 100 & 81 & 83 & 0 \\
\hline V & 265 & 29 & 10 & 12 & 21 & 24 & 0 & 1 & 20 & 48 \\
\hline W & 41 & 0 & 100 & 23 & 0 & 12 & 0 & 113 & 0 & 0 \\
\hline Y & 161 & 21 & 50 & 20 & 0 & 9 & 0 & 128 & 28 & 0 \\
\hline C & 44 & 0 & 28 & 27 & 20 & 0 & 19 & 79 & 60 & 45 \\
\hline G & 261 & 15 & 26 & 100 & 16 & 0 & 11 & 77 & 12 & 0 \\
\hline N & 158 & 0 & 30 & 16 & 21 & 11 & 0 & 313 & 24 & 0 \\
\hline Q & 69 & 282 & 50 & 29 & 0 & 16 & 0 & 19 & 64 & 4 \\
\hline S & 87 & 35 & 27 & 20 & 0 & 28 & 0 & 28 & 38 & 0 \\
\hline T & 84 & 116 & 8 & 21 & 0 & 19 & 0 & 8 & 63 & 24 \\
\hline D & 0 & 0 & 36 & 18 & 16 & 100 & 13 & 7 & 0 & 0 \\
\hline E & 0 & 0 & 23 & 22 & 9 & 0 & 15 & 0 & 0 & 0 \\
\hline H & 85 & 0 & 39 & 49 & 24 & 0 & 20 & 78 & 0 & 14 \\
\hline K & 287 & 0 & 21 & 28 & 16 & 0 & 19 & 245 & 57 & 0 \\
\hline R & 320 & 0 & 41 & 20 & 0 & 21 & 0 & 129 & 29 & 0 \\
\hline
\end{tabular}

Figure 2.

Mutational scan of the 1E6 CD8 ${ }^{+} \mathrm{T}$ cell clone. Single mutations at each of the 10 positions in the ALWGPDPAAA peptide to each of the 19 other proteogenic amino acids were assessed for their ability to induce TNF secretion (data shown is average of 3 experiments). The index peptide was normalized to a response of 100 (black text with yellow background). Mutations that decreased the response to below 25 compared to index sequence are shown in pink. Nonpolar hydrophobic mutations are shown in orange, polar hydrophobic mutations are shown in green, polar uncharged mutations are shown in blue, acidic mutations are shown in red and basic mutations are shown in white. 

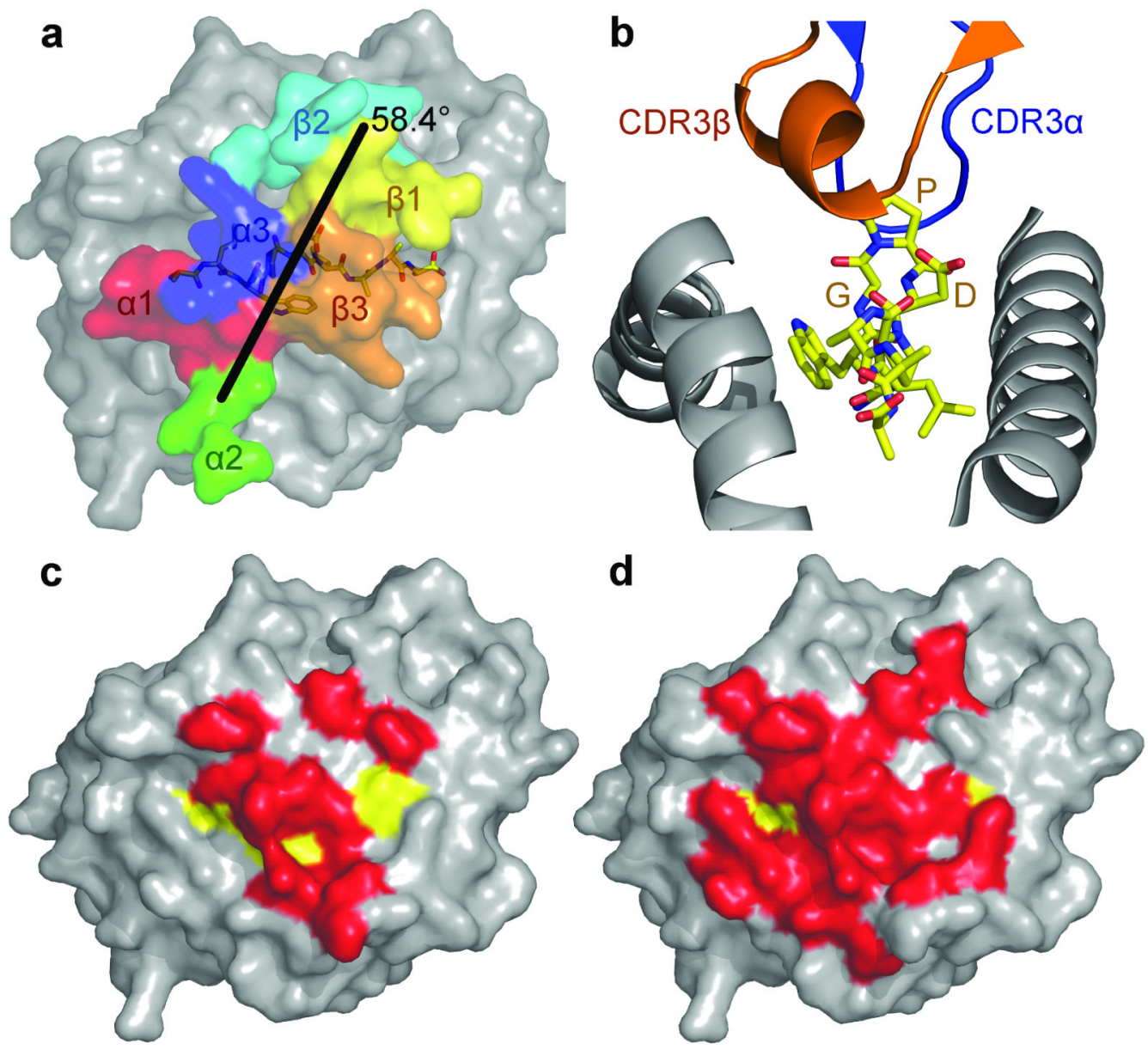

Figure 3.

(a) The positions of the TCR CDR loops (CDR1a, red; CDR2a, green; CDR3a, blue; CDR1 $\beta$, yellow; CDR2 $\beta$, cyan; CDR3 $\beta$, orange) in the co-complex structure between the 1E6 TCR and the preproinsulin-derived peptide ALWGPDPAAA (ALW) (yellow sticks) bound to HLA A*0201 (grey surface). The crossing angle of the TCR (58.4 ${ }^{\circ}$ ) is shown. (b) View down the centre of the MHC binding groove (ALW shown in yellow sticks) illustrating the perpendicular binding conformation of the TCR CDR3 $a$ (blue) and CDR3 $\beta$ (orange) loops. (c) Surface representation of the binding footprint of the 1E6 TCR over A2ALW (A2 is shown as grey surface and the ALW is shown as yellow surface). A2-ALW residues that were contacted by the 1E6 TCR are shown in red. (d) Surface representation of the binding footprint of the AS01 TCR over A2-GLC ${ }^{11}$ (A2 is shown as grey surface and the GLC is shown as yellow surface). A2-GLC residues that were contacted by the AS01 TCR, calculated using a $3.2 \AA$ cut-off for H-bonds and $4 \AA$ cut-off for vdW contacts, are shown in red. The comparison of the surface contacts between the 1E6 TCR and AS01 TCR demonstrates the more focussed minimal contact zone implemented by the 1E6 TCR when binding to A2-ALW. 


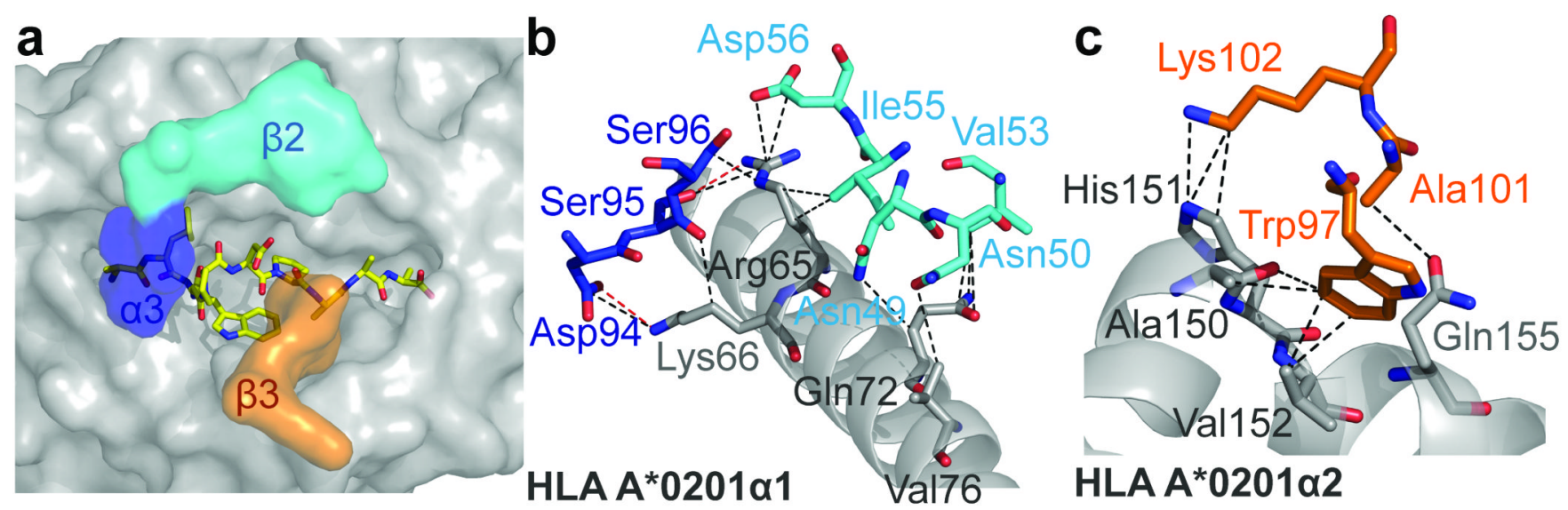

Figure 4.

(a) Surface representation of the TCR CDR loop (CDR3a, blue; CDR2 $\beta$, cyan; CDR3 $\beta$, orange) residues that contact the MHC surface. (B) Contacts between the TCR and the MHCa 1 domain. The TCR CDR3a and the TCR CDR2 $\beta$ and CDR3 $\beta$ loops made a number of vdW (black dotted lines) and H-bond (red dotted lines) contacts with the MHCa 1 central domain, including residue Arg65, which is part of the MHC restriction triad ref. (c) Contacts between the TCR $\beta$-chain CDR3 $\beta$ loop and the MHCa 2 domain. These important stabilizing interactions included a vdW contact with the gatekeeper residue Gln 155 . 


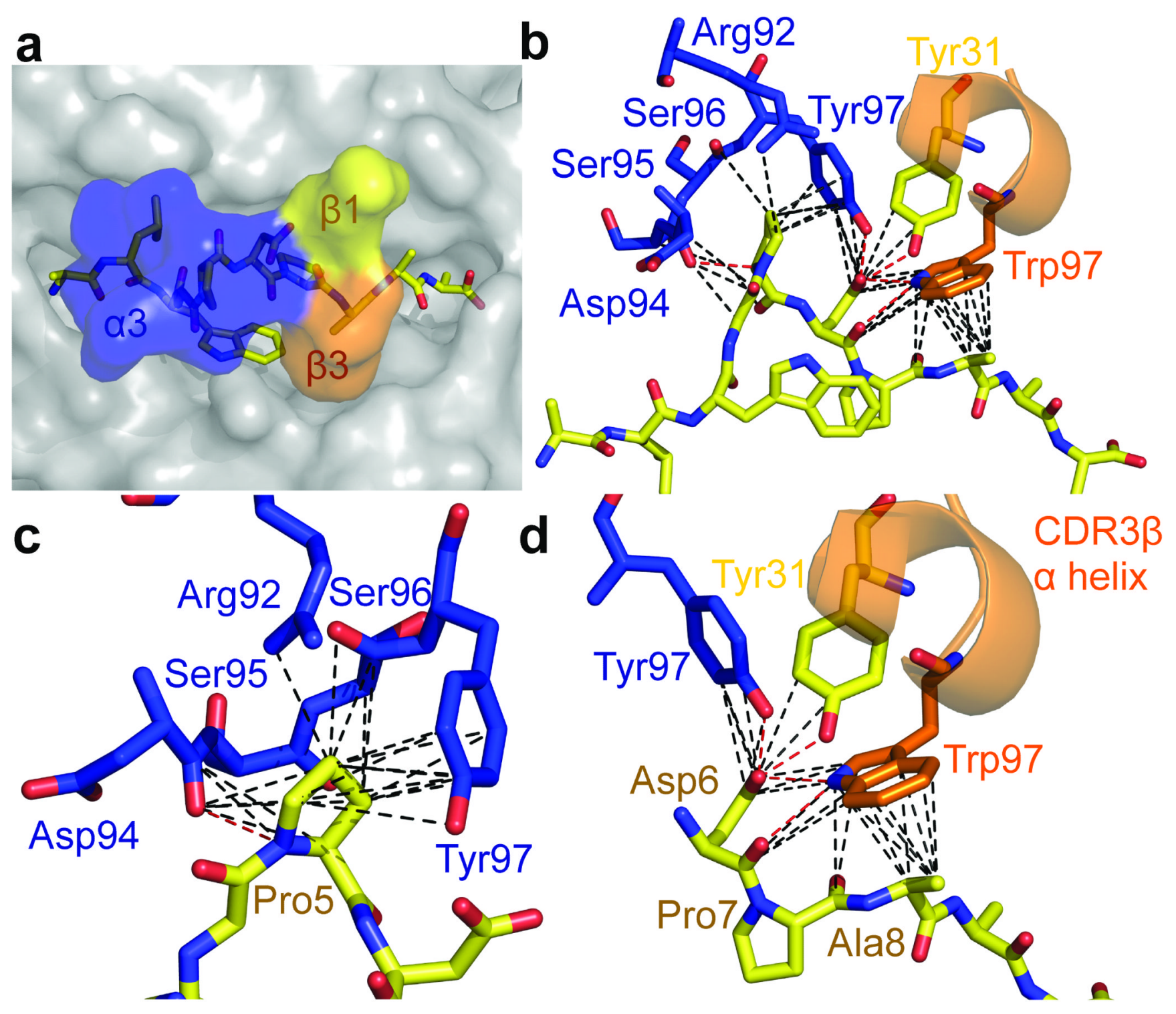

Figure 5.

(a) Surface representation of the TCR residues (CDR3a, blue; CDR1 $\beta$, yellow; CDR3 $\beta$, orange) that contact the peptide. (b) Main contacts between the TCR and the peptide. TCR CDR $3 a$ and the TCR CDR $1 \beta$ and CDR3 $\beta$ loops made a number of vdW contacts (black dotted lines) and H-bonds (red dotted lines) with the central GPDPA motif of the ALWGPDPAAA (ALW) peptide (yellow sticks). (c) Contacts between the ALW residue Pro5 (yellow sticks) and the TCR CDR3a loop (blue sticks). The prominent exposed central position of Pro5 resulted in a number of important contacts between the TCR and the ALW peptide. (d) Contacts between the TCR CDR1 $\beta$ and CDR3 $\beta$ loops and the C-terminus of the peptide in which Asp6 was the major contact residue. Additionally, the dominant role of the TCR $\beta$-chain residue Trp97 (orange sticks) during peptide binding is illustrated. Trp97 is the only CDR3 $\beta$ loop residue that contacted the peptide, making a number of vdW contacts (black dotted lines) and H-bonds (red dotted lines) with Asp6, Pro7 and Ala8 in the ALW peptide. 


\section{Table 1}

Binding affinity analysis the 1E6-ALW complex

\begin{tabular}{|l|l|l|}
\hline Temp $\left({ }^{\circ} \mathbf{C}\right)$ & $\mathbf{K}_{\mathbf{D}} \boldsymbol{\mu M}$ & $\Delta \mathbf{G}_{\mathbf{0}} \mathbf{K c a l} / \mathbf{m o l}$ \\
\hline 5 & $274.5 \pm 14$ & -4.5 \\
\hline 25 & $278 \pm 7.6$ & -4.8 \\
\hline 37 & $335 \pm 44$ & -4.9 \\
\hline
\end{tabular}


N
$\frac{0}{0}$
은

\begin{tabular}{|c|c|c|c|c|c|c|c|c|c|c|c|c|c|c|c|c|c|c|c|c|c|c|c|c|c|c|}
\hline 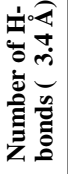 & & & 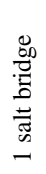 & & & - & & - & & & & & & & - & & - & & & & & & & & & \\
\hline 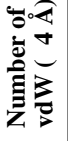 & - & $\sim$ & & $\nabla$ & 0 & & - & & - & $\sim$ & $m$ & $\nabla$ & $\cong$ & in & & $N$ & & -1 & -1 & $m$ & $\sim$ & $\sim$ & $N$ & $N$ & - & $m$ \\
\hline 邑兽 & & 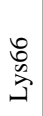 & 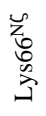 & & & & $\begin{array}{l}n \\
0 \\
0 \\
2 \\
2\end{array}$ & 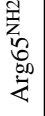 & 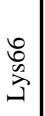 & & $\begin{array}{l}n \\
0 \\
\dot{0} \\
\dot{z}\end{array}$ & & & & & & & 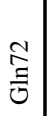 & $\begin{array}{l}\stackrel{0}{\circ} \\
\stackrel{5}{5}\end{array}$ & $\stackrel{\mathbb{\Xi}}{\cong}$ & 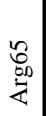 & $\begin{array}{l}n \\
0 \\
0 \\
\dot{z}\end{array}$ & $\frac{\frac{n}{n}}{\frac{\pi}{4}}$ & 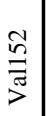 & $\begin{array}{l}\frac{n}{n} \\
\frac{\Xi}{0} \\
0\end{array}$ & $\frac{\bar{n}}{\bar{n}}$ \\
\hline 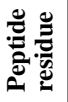 & $\stackrel{n}{2}$ & & & 丞 & $\stackrel{n}{2}$ & $\begin{array}{l}z \\
i n \\
\vdots \\
\vdots \\
2\end{array}$ & & & & $\stackrel{n}{2}$ & & $\stackrel{n}{2}$ & $\stackrel{2}{2}$ & 足 & 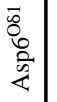 & 号 & 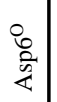 & & & & & & & & & \\
\hline 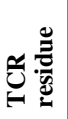 & $\begin{array}{l}\Omega \\
\text { bे } \\
\dot{z}\end{array}$ & $\begin{array}{l}\frac{1}{2} \\
\frac{2}{2}\end{array}$ & 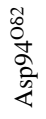 & $\begin{array}{l}\text { वे } \\
\text { के } \\
\text { दे }\end{array}$ & $\begin{array}{l}\text { वे } \\
\frac{\hat{\alpha}}{2}\end{array}$ & $\begin{array}{l}0 \\
0 \\
0 \\
\frac{2}{2}\end{array}$ & $\begin{array}{l}\approx \\
\hat{D} \\
n\end{array}$ & 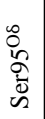 & 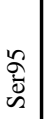 & 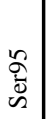 & 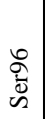 & 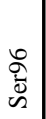 & 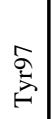 & 育 & 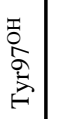 & $\overrightarrow{\stackrel{D}{\rightleftarrows}}$ & 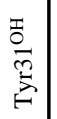 & 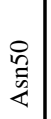 & 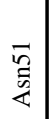 & $\underset{\frac{n}{n}}{\stackrel{n}{\infty}}$ & 党 & $\begin{array}{l}2 \\
2 \\
\frac{2}{2} \\
2\end{array}$ & $\hat{\hat{E}}$ & $\begin{array}{l}\hat{\hat{a}} \\
\hat{B}\end{array}$ & $\begin{array}{l}\frac{\sigma}{0} \\
\frac{\pi}{2}\end{array}$ & $\frac{\sigma}{\frac{\sigma}{\omega}}$ \\
\hline 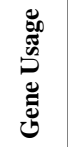 & 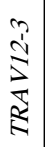 & $\begin{array}{l}\frac{1}{3} \\
\frac{7}{8}\end{array}$ & 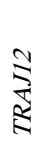 & 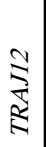 & $\begin{array}{l}\frac{1}{3} \\
\frac{7}{k}\end{array}$ & \begin{tabular}{l}
\multirow{2}{*}{} \\
\multirow{2}{*}{}
\end{tabular} & 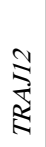 & 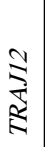 & 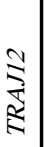 & 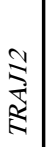 & 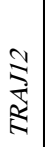 & $\underset{\Sigma}{\stackrel{5}{*}}$ & 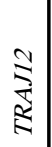 & \begin{tabular}{l}
\multirow{2}{*}{} \\
$\frac{3}{3}$
\end{tabular} & $\begin{array}{l}\frac{1}{3} \\
\frac{7}{3}\end{array}$ & 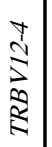 & 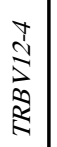 & 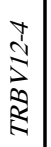 & 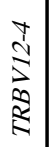 & 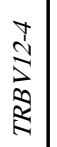 & 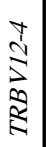 & 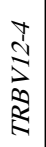 & 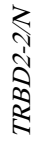 & 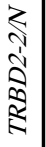 & 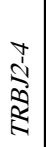 & 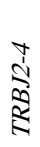 \\
\hline Оิ & 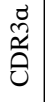 & & & & & & & & & & & & & & & $\begin{array}{l}\stackrel{0}{\vec{n}} \\
\vec{\theta}\end{array}$ & & $\begin{array}{l}\stackrel{0}{\widetilde{z}} \\
\stackrel{\tilde{\Xi}}{0}\end{array}$ & & & & & 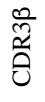 & & & \\
\hline
\end{tabular}

Nat Immunol. Author manuscript; available in PMC 2012 September 01. 


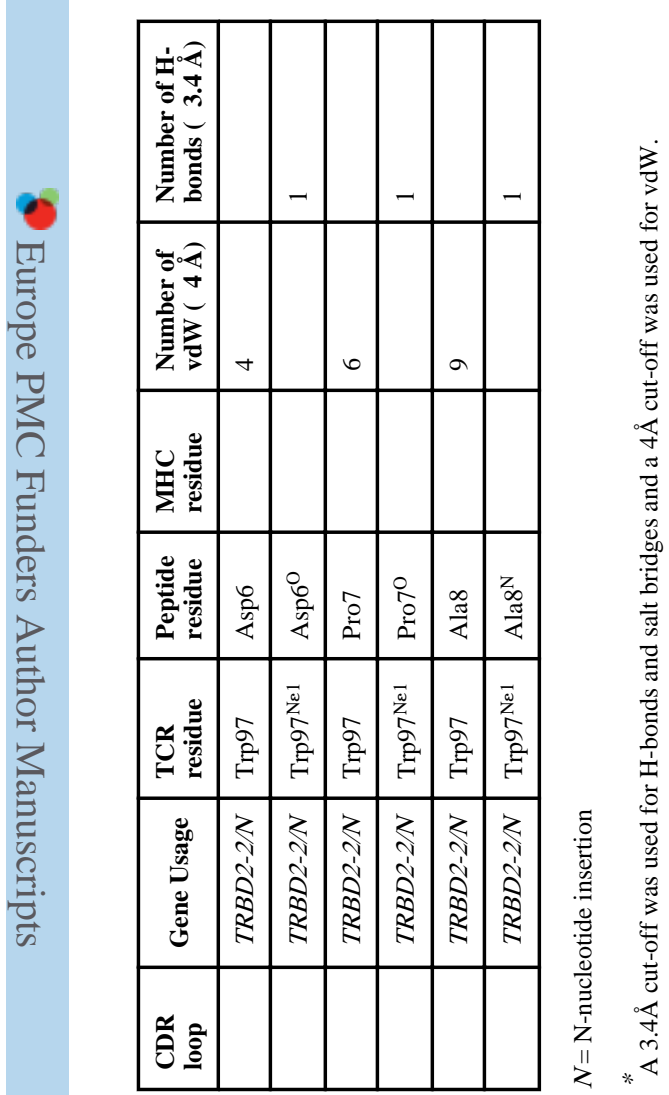

